\title{
Article \\ A Comparative Study on the Anti-Corrosive Performance of Zinc Phosphate in Powder Coatings
}

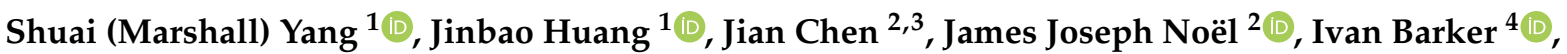 \\ Jeffrey Daniel Henderson ${ }^{4}{ }^{\infty}$, Ping He ${ }^{5}$, Haiping Zhang ${ }^{6}$, Hui Zhang ${ }^{1, *}$ and Jesse Zhu ${ }^{1}$
}

check for

updates

Citation: Yang, S.; Huang, J.; Chen, J.; Noël, J.J.; Barker, I.; Henderson, J.D.; He, P.; Zhang, H.; Zhang, H.; Zhu, J. A Comparative Study on the Anti-Corrosive Performance of Zinc Phosphate in Powder Coatings. Coatings 2022, 12, 217. https:// doi.org/10.3390/coatings12020217

Academic Editor: Sergey N. Grigoriev

Received: 28 December 2021

Accepted: 31 January 2022

Published: 7 February 2022

Publisher's Note: MDPI stays neutral with regard to jurisdictional claims in published maps and institutional affiliations.

Copyright: (C) 2022 by the authors. Licensee MDPI, Basel, Switzerland. This article is an open access article distributed under the terms and conditions of the Creative Commons Attribution (CC BY) license (https:// creativecommons.org/licenses/by/ $4.0 /)$.

1 Department of Chemical and Biochemical Engineering, Western University, London, ON N6A 5B9, Canada; marshall.yang@uwo.ca (S.Y.); jhuan467@uwo.ca (J.H.); jzhu@uwo.ca (J.Z.)

2 Department of Chemistry, Western University, London, ON N6A 5B7, Canada; jchen@imr.ac.cn (J.C.); jjnoel@uwo.ca (J.J.N.)

3 Key Laboratory of Nuclear Materials and Safety Assessment, Institute of Metal Research, Chinese Academy of Sciences, Shenyang 110016, China

4 Surface Science Western, Western University, London, ON N6G 0J3, Canada; ivan.barker@uwo.ca (I.B.); jhende64@uwo.ca (J.D.H.)

5 School of Materials Science and Engineering, Southwest University of Science and Technology, Mianyang 621010, China; heping@swust.edu.cn

6 Collaborative Innovation Center of Chemical Science and Engineering (Tianjin), School of Chemical Engineering and Technology, Tianjin University, Tianjin 300072, China; hpzhang@tju.edu.cn

* Correspondence: hzhang1@uwo.ca; Tel.: +1-519-661-2111 (ext. 81294)

Abstract: Powder coatings are gaining popularity for their economic and environmental benefits Additives (pigments) such as zinc phosphate enhance the anti-corrosive properties of coatings, but their behavior in powder coatings has not been extensively studied. In this study, zinc phosphate was incorporated into three powder coating systems: polyester clearcoat, polyester and epoxy coatings with filler $\mathrm{BaSO}_{4}$. Neutral salt spray and electrochemical tests (OCP, LPR, and EIS) confirmed that the anti-corrosive performance improved with the addition of zinc phosphate. The optimal additive dosage was determined to be $2 \%$ for all of the coating systems studied here, based on salt spray tests. Here, the time until failure increased by 1.5 to 2 times. Using electrochemical tests, an optimal additive dosage of $8 \%$ was found for the polyester clearcoat, while the other coating systems maintained an optimal additive dosage of $2 \%$. Performance increased by as much as one order of magnitude based on resistance/impedance measurements. This suggested a synergistic effect between the additive and the filler. The passivation layer was confirmed by both X-ray diffraction and Raman spectroscopy. Based on the results and discussion presented in this article, the discrepancy was caused by different features of the two tests, such that the electrochemical tests probe the function of intact coatings, whereas salt spray measures only the corrosion spreading from the scribe. It is proposed that the two test methods characterize different aspects of the coatings, corresponding to their service conditions. This has theoretical and practical significance in the evaluation of anti-corrosive coatings. Other properties of the coatings, including adhesion, gloss, distinctness-of-image, and pencil hardness, were measured as per applicable standards and the conformance was verified.

Keywords: powder coatings; anti-corrosive; zinc phosphate; additive; pigment; filler; EIS; electrochemical impedance spectroscopy

\section{Introduction}

Corrosion of metals is ubiquitous in both natural and industrial environments, causing visual quality deterioration of materials, mechanical failures, and safety related incidents. In a pH-neutral environment with dissolved oxygen, metal oxidizes as the anode and oxygen is reduced at the cathode [1]. Paints and coatings are widely used to mitigate corrosion of metallic substrates, such as steel, aluminum, etc., by functioning as a shielding 
layer on the metallic substrate to prevent contact between the substrate and any corrosive media in service. Furthermore, the paints and coatings separate the local anodic and cathodic regions in the substrate by a physical barrier and other mechanisms [2]. While both liquid and powder coatings are available for this purpose, powder coatings have advantages over their liquid counterparts. Powder coatings eliminate the use of VOCs (Volatile Organic Compounds) as solvents, and have relatively lower material cost and energy consumption [3,4].

Powder coatings can be classified into thermoplastic and thermosetting types. Both powder coating types are used for the same functional purposes of protecting metals from corrosion, however comparatively, thermosetting powder coatings can achieve a denser film by a cross-linking reaction between the resin and the curing agent. As a result, they can provide better corrosion resistance, chemical resistance, and mechanical properties than thermoplastic powder coatings [5,6]. Given this clear advantage of the thermosetting powder coatings, this study utilizes thermosetting powder coatings to achieve high corrosion protection.

The main components of thermosetting powder coatings include binder (the combination of resin and curing agent), pigments, fillers, and various additives [7]. Thermosetting powder coatings are available with polyester, epoxy, polyester/epoxy hybrid, polyurethane, polyacrylate binders, etc. Amongst these, epoxy is the primary choice for marine and protective coatings due to its superior adhesion to the metallic substrate and high anti-corrosive performance [5]. However, the ether group in its polymer chain renders it prone to chalk (a degradation mechanism in which the coating turns into a loose powder) under outdoor UV exposure [1,8]. Epoxy-coated parts can only be used under adequate coverage by other elements, e.g., for automotive components under the hood or used as a primer under topcoats. The application of a multilayer system increases the complexity, cost, and risk of potential defects like poor inter-coat adhesion between two different coats $[9,10]$. Therefore, a single-layered coating is preferable if it can meet all the requirements for the coating properties.

Incorporating additives into the binder can further enhance the anti-corrosive property of the coating. The anti-corrosive additives (also classified as pigments in research and industrial practices) function through different mechanisms, including barrier effect [11], galvanic effect [12], and chemical inhibition [13]. The inhibitive additives are commonly inorganic salts such as phosphates and silicates, which have gone through four generations of development and improvement [14-17]. The first generation of additives were composed of zinc phosphate, however later generations include zinc aluminum phosphate [18], potassium zinc phosphate [16,19], zinc aluminum molybdenum orthophosphate, zinc calcium strontium aluminum orthophosphate silicate [15], lithium zinc phosphate [20], and other additives that do not contain zinc, such as strontium aluminum polyphosphate (SAPP) [21].

Puig et al. [22] investigated the anti-corrosive performance of zinc molybdenum phosphate and organo-modified silica mixtures compared to their separate use in powder coatings. A synergistic effect was found between the two, using a relatively high additive dosage at $10 \%$. Similarly, surface-modified zinc molybdenum phosphate at $10-15 \%$ was required to achieve optimal performance in a polyester powder coating [23]. Of the four generations of phosphate additives, zinc phosphate remains the most economical and environmentally benign option. Generally, the inhibitive additive is activated in the event of localized coating failure and substrate corrosion. The metal cations generated by the corrosion react with the anion released by the additive to form a sediment of lower solubility [24], in this way, the localized corrosion spot is blocked and protected from further corrosion by a formed passivation layer, and the coating is imparted self-healing and selfrepairing ability [13]. At the localized corrosion sites, this passivation layer functions as a barrier to inhibit further corrosion propagation.

Other thermosetting coating components, such as pigments [18,25] and fillers [26,27], can also influence the coating performance [5]. The addition of fillers (also called extenders) 
into powder coating is common in the industry. The filler can lower the cost of the product and enhance the mechanical properties of the produced coating films [28,29]. These solid particles can also contribute to the barrier effect of the coating films by increasing their tortuosity $[29,30]$. However, the interactions amongst these components and their combined effects have not been extensively investigated.

Neutral salt spray tests are widely used in industry to assess the anti-corrosive property of coatings. However, they cannot provide detailed information on the coating properties during the test. In this study, electrochemical techniques are utilized to compare with the salt spray test results. The open circuit potential (OCP, or Ecorr) and linear polarization resistance $\left(R_{p}, L P R\right)$ values are easy to measure and interpret in the immersion test. They are used to determine the optimal dosage in each series of formulae; higher OCP and $R_{p}$ values indicate a better protective function of the coating films [31-33]. In addition, electrochemical impedance spectroscopy (EIS) was performed on the metal coated using films prepared with the optimal additive dosage in each series to monitor the detailed coating transition over time. The EIS spectra can be interpreted by the numeric values of electrical components obtained from the equivalent electrical circuit (EEC) data fitting process [34-36].

In this study, the anti-corrosive behavior of a commercially available zinc phosphate additive was investigated. The additive was formulated into a prior optimized polyester/TGIC (triglycidyl isocyanurate) powder coating binder at a series of dosages. In the second series of formulae, a filler $\mathrm{BaSO}_{4}$ was incorporated in addition to the additive to evaluate their combined effect. The third series of formulae with a prior optimized epoxy/DICY (dicyandiamide) binder and the same filler content was compared with the two polyester systems. Both neutral salt spray and electrochemical tests were employed and the results were compared.

\section{Materials and Methods}

\subsection{Materials and Coating Formulae}

A cost-effective anti-corrosive additive HALOX ${ }^{\circledR}$ CZ-170 (ZP) was evaluated and optimized in polyester/TGIC and epoxy/DICY powder coating systems. The properties of this additive are listed in Table 1. Its relatively small particle size and narrow particle size distribution facilitated the dispersion in the binders. In addition to zinc phosphate $(60-80 \%$ mass fraction), the additive contains zinc oxide (20-35\% mass fraction), which has passive anti-corrosive function $[37,38]$.

Table 1. Properties of the anti-corrosive additive HALOX CZ-170.

\begin{tabular}{|c|c|c|c|c|c|c|c|}
\hline Additive & $\begin{array}{c}\text { Particle Size } \\
\left(D_{10}\right) /(\mu \mathrm{m})\end{array}$ & $\begin{array}{c}\text { Particle Size } \\
\left(D_{50}\right) /(\mu \mathrm{m})\end{array}$ & $\begin{array}{c}\text { Particle Size } \\
\left(D_{90}\right) /(\mu \mathrm{m})\end{array}$ & $\begin{array}{l}\text { Oil Absorption/ } \\
\text { (g oil/100 g) }\end{array}$ & $\begin{array}{l}\mathrm{pH}, 10 \% \text { in } \mathrm{D} . \\
\text { I. Water }\end{array}$ & $\begin{array}{r}\text { Solubility in } \\
\text { Water /(wt.\%) }\end{array}$ & Density $/\left(\mathrm{g} / \mathrm{cm}^{3}\right)$ \\
\hline HALOX $^{\circledR}$ CZ-170 & 0.57 & 2.48 & 6.56 & 43.5 & 10.0 & 0.02 & 3.6 \\
\hline
\end{tabular}

The binder compositions of the polyester/TGIC and epoxy/DICY systems are listed in Table 2. For studying the effect of filler $\mathrm{BaSO}_{4}$ on the properties of the two coatings in addition to the additive, three series of coating formulae PC, PB and EB, as listed in Table 3, were evaluated and compared. The polyester/TGIC and epoxy/DICY systems with the filler were tinted with a small amount of carbon black. 
Table 2. Binder formulae of polyester/TGIC powder clearcoat (PC), black polyester/TGIC (PB), and black epoxy/DICY (EB) powder coatings.

\begin{tabular}{|c|c|c|c|}
\hline Coating Binder & Component & Composition & Content/(wt. \%) \\
\hline \multirow{5}{*}{ Polyester/TGIC (PC) } & resin & carboxylated polyester & 90.78 \\
\hline & curing agent & TGIC & 6.75 \\
\hline & flow and leveling agent & polyacrylate with silica & 1.65 \\
\hline & degassing agent & benzoin & 0.82 \\
\hline & pigment & $\mathrm{N} / \mathrm{A}$ & 0.00 \\
\hline \multirow{5}{*}{ Polyester/TGIC (PB) } & resin & carboxylated polyester & 90.04 \\
\hline & curing agent & TGIC & 6.70 \\
\hline & flow and leveling agent & polyacrylate with silica & 1.64 \\
\hline & degassing agent & benzoin & 0.82 \\
\hline & pigment & high color carbon black for automotive coatings & 0.80 \\
\hline \multirow{5}{*}{ Epoxy/DICY (EB) } & resin & epoxy, epoxide equivalent weight $(E E W)=730 \sim 820 \mathrm{~g} / \mathrm{eq}$ & 89.00 \\
\hline & curing agent & DICY & 7.73 \\
\hline & flow and leveling agent & polyacrylate with silica & 1.65 \\
\hline & degassing agent & benzoin & 0.82 \\
\hline & pigment & high color carbon black for automotive coatings & 0.80 \\
\hline
\end{tabular}

Table 3. Coating formulae in polyester/TGIC clear binder (PC), black polyester/TGIC with filler $(\mathrm{PB})$, and black epoxy/DICY with filler (EB).

\begin{tabular}{ccccc}
\hline Coating Systems & Formula Code & ZP/(wt. \%) & Filler BaSO $/$ (wt. \%) & Binder/(wt. \%) \\
\hline & Control-PC & 0.0 & 0.0 & 100.0 \\
Polyester/TGIC clearcoat (PC) & ZP-02\%-PC & 2.0 & 0.0 & 98.0 \\
& ZP-04\%-PC & 4.0 & 0.0 & 96.0 \\
& ZP-08\%-PC & 8.0 & 0.0 & 92.0 \\
& ZP-16\%-PC & 16.0 & 0.0 & 84.0 \\
\hline & Control-PB & 0.0 & 15.0 & 83.0 \\
Polyester/TGIC with filler BaSO 4 (PB) & ZP-02\%-PB & 2.0 & 14.7 & 81.6 \\
& ZP-04\%-PB & 4.0 & 14.4 & 78.2 \\
& ZP-08\%-PB & 8.0 & 13.8 & 71.4 \\
\hline & ZP-16\%-PB & 16.0 & 12.6 & 85.0 \\
Epoxy/DICY with filler BaSO & Control-EB & 0.0 & 15.0 & 83.3 \\
& ZP-02\%-EB & 2.0 & 14.7 & 81.6 \\
& ZP-04\%-EB & 4.0 & 14.4 & 78.2 \\
& ZP-08\%-EB & 8.0 & 13.8 & 71.4 \\
\hline
\end{tabular}

\subsection{Preparation of Coating Powder and Coated Panels}

The raw materials were pre-mixed and fed into a twin-screw extruder (model No. SLJ-10, Donghui Powder Coating Equipment Co., Yantai, China). The temperatures of the infeed, plastification, and homogenizing zones remained constant at 80,90 , and $100{ }^{\circ} \mathrm{C}$, respectively. The screw speed and roller chiller speeds were kept constant at 300 and $10 \mathrm{rpm}$, respectively. The formed chips were pulverized using a benchtop grinder, and the ground coating powders were sieved to have a median particle size $\left(D_{50}, \mathrm{v}\right)$ of $35 \pm 3 \mu \mathrm{m}$.

Phosphated steel panels $(76 \mathrm{~mm} \times 152 \mathrm{~mm} \times 0.81 \mathrm{~mm}$, ASTM D609 Type 2) by Q-Lab Corporation (Cleveland, OH, USA) were used as the substrate. The powder coatings were electrostatically sprayed using Gema OptiSelect corona charged gun and OptiStar gun control unit (Gema Switzerland GmbH, Gallen, Switzerland), and the voltage remained constant at $-35 \mathrm{kV}$. The panels were prepared with good edge coverage, due to the wrapup effect of the electrostatically charged powder cloud during spraying. The visually defect-free panels, without craters and pinholes, were used for performance evaluation and characterization. All the film thicknesses were controlled to be $60 \pm 5 \mu \mathrm{m}$. 


\subsection{Characterization and Evaluation Techniques}

\subsubsection{Electrochemical Measurements}

Each test panel was immersed in $5 \% \mathrm{NaCl}$ in type-I water $(18.2 \mathrm{M} \Omega \cdot \mathrm{cm}$ resistivity) and connected as the working electrode in a standard three-electrode system. A saturated calomel electrode (SCE) and a Pt plate were used as the reference and counter electrodes, respectively. A Solartron ModuLab XM materials test system (AMETEK Process and Analytical Instruments, Pittsburgh, PA, USA) was used for electrochemical measurements and control of the system. The electrochemical cell was housed in a Faraday cage for all the electrochemical measurements, including OCP, $\mathrm{R}_{\mathrm{p}}$, and EIS. The measurements were performed every $24 \mathrm{~h}$ during an extended exposure period to monitor changes in the coating film over time. The first data points on Day 0 correspond to the values of 30 min immersion.

The $R_{p}$ was measured in the pseudo-linear region of $\mathrm{OCP} \pm 10 \mathrm{mV} D C$ at a scan rate of $10 \mathrm{mV} / \mathrm{min}$, and the $R_{\mathrm{p}}$ value was determined from the slope of the $E-i$ (potential-current density) curve. The EIS scanning was performed in the frequency range between 10 and $100 \mathrm{kHz}$ using an OCP $\pm 10 \mathrm{mV}$ AC (peak-to-peak) sinusoidal perturbation. The EIS spectra analysis by least-squares fitting was performed using the software ZView version 4.0c (Scribner Associates, Southern Pines, NC, USA).

\subsubsection{Salt Spray Tests}

The salt spray tests for evaluating the anti-corrosive property of the coated panels were conducted in the neutral salt spray chamber MX-9204 (Associated Environmental Systems, Ayer, MA, USA) as per ISO 9227:2017 and was evaluated according to ISO 4628-8:2012. Two intersecting scribes of $0.5 \mathrm{~mm}$ were generated on each panel for the tests, following the standard practice for testing the anti-corrosive property in the powder coating industry.

\subsubsection{General Coating Property Measurements}

The coating film thicknesses were measured by a PosiTector 6000 (DeFelsko Corporation, Ogdensburg, NY, USA) as per ASTM D7091-13. The pencil hardness and adhesion of the coating films were measured using a BYK 5800 pencil hardness tester (BYK Gardner USA, Columbia, MD, USA) and Elcometer 107 cross hatch cutter (Elcometer Limited, Manchester, UK) following ASTM D3363-05 (Reapproved 2011) and ASTM D3359-09, respectively.

The coating surface quality was assessed by a Rhopoint IQ 20/60 gloss meter (Rhopoint Instruments Ltd., St Leonards on Sea, UK), measuring the specular gloss and DOI (distinctness-of-image), as per ASTM D523-14 and D5767-18, respectively.

\subsubsection{Imaging and Spectroscopy Analyses}

The scanning electron microscopy (SEM) imaging and energy dispersive X-ray (EDX) mapping were performed in secondary electron mode on a SU3500 (Hitachi, Tokyo, Japan) scanning electron microscope coupled with an Oxford ULTIM MAX 65 SDD X-ray analyzer. The Raman spectroscopy was performed on an InVia Reflex Raman Spectrometer (Renishaw plc, Gloucestershire, UK) at a laser wavelength of $633 \mathrm{~nm}$ to identify corrosion products after the salt spray tests. A Rigaku SmartLab automated multipurpose X-ray diffractometer (XRD, Rigaku Corporation, Akishima, Japan) system equipped with Cross Beam Optics (CBO) system and a 2D HyPix-3000 detector was also used to characterize the corrosion products for a larger coated surface area of approximately $70 \mathrm{~mm} \times 70 \mathrm{~mm}$. Low grazing incident $\mathrm{XRD}$ with an incident angle of $3^{\circ}$ was used for the measurement.

\section{Results and Discussion}

\subsection{Evaluation Results of Coating Properties}

The incorporation of the solid particles did not affect the coating adhesion and pencil hardness. The coated panels of all three series formulae had good adhesion of $4 \mathrm{~B}$. The pencil hardness values of the coatings prepared by the four formulae with ZP dosages of 2, 4, 6, 8, and $16 \%$ were all measured $\mathrm{HB}$ in the three systems, being the same as the clearcoat Control-PC. 
The specular gloss at $60^{\circ}$ and DOI values of the coatings prepared by the three series of formulae are plotted in Figure $1 \mathrm{a}, \mathrm{b}$. Generally, the gloss and DOI values decreased with the ZP content in the coating films, caused by the higher surface roughness $[39,40]$. The higher roughness could lead to lower effective film thickness, causing a decrease in protective function. It was also observed that the addition of $\mathrm{BaSO}_{4}$ filler further decreased the two values, as increasing the solid content hindered the flow and leveling of coating films. These results normally still meet the requirements of anti-corrosive applications in the industry.
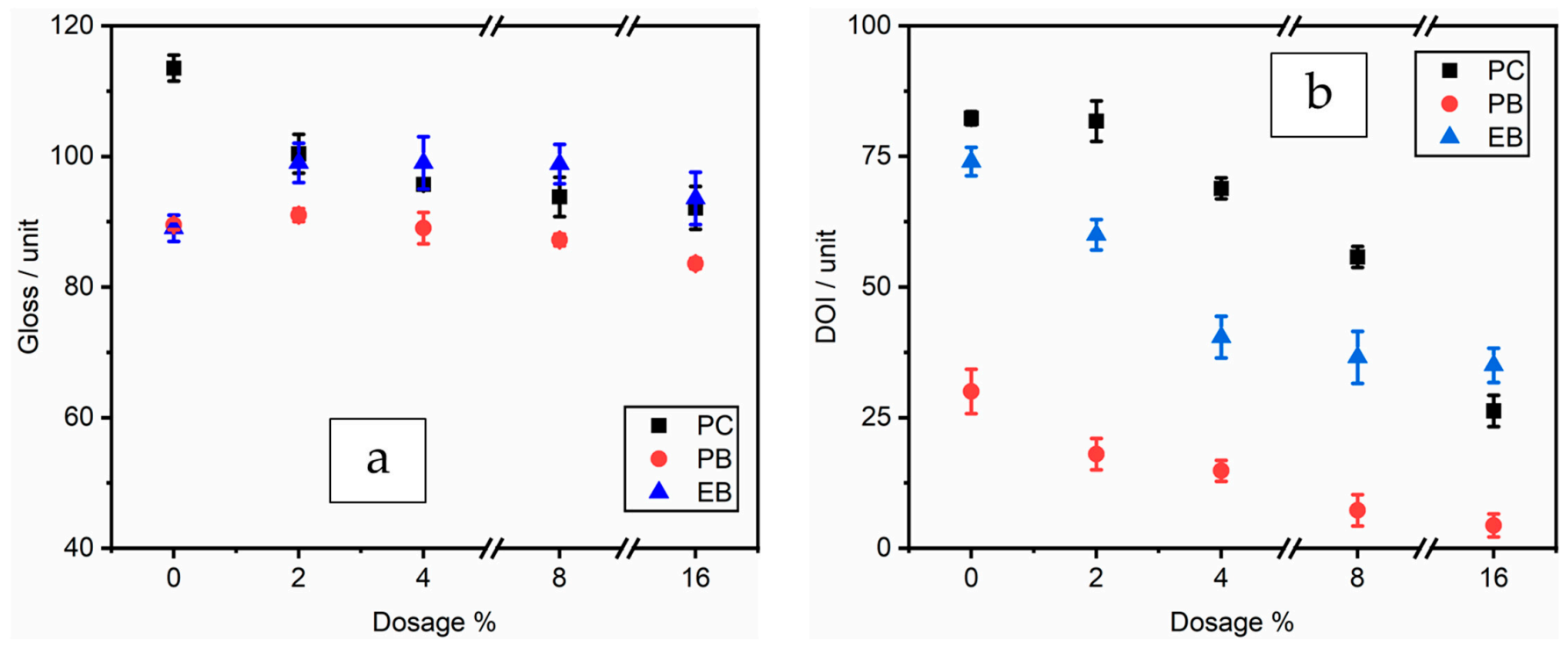

Figure 1. Gloss (a) and DOI (b) values of ZP in PC, PB, and EB.

\subsection{Coating Morphologies}

The SEM image in Figure 2a shows the original additive morphology. Figure $2 \mathrm{~b}-\mathrm{f}$ shows the cross-section images of coating films prepared by the formulae with different $\mathrm{ZP}$ dosages in the three binders. As seen in these images, the additive and filler achieved good dispersion, as demonstrated by their small particle sizes in the binder polymer matrix. As confirmed in the EDX maps in Figure $2 \mathrm{~m}-\mathrm{O}$, the additive $\mathrm{ZP}$ achieved smaller particle sizes at the dosage of $2 \%$ with the presence of the filler than in the clearcoat, as the filler functioned as a dispersing aid, and the increased viscosity of the coating system by incorporating the filler was also beneficial to the dispersion during extrusion [41,42]. However, as shown in Figure $2 \mathrm{i}, 1$, the additive dosage at $4 \%$ led to larger numbers of voids in the binder, which was detrimental to the barrier and shielding properties of the coatings. All test panels with coatings prepared by other formulae exhibited dense and compact inner structures.

\subsection{Electrochemical Measurement Results}

\subsubsection{OCP and $R_{p}$ Results}

Figure 3 ( $a, d, P C ; b, e, P B ; c, f, E B)$ shows the measured OCP and $R_{p}$ values. These two values are indicators for the overall barrier and shielding functions of different formulae. The initial OCP of the uncoated substrate was measured to be $-617.00 \mathrm{mV}$. Higher OCP and $R_{p}$ values demonstrated that the substrate was better protected, and defects inside the coating film were less numerous $[43,44]$. 

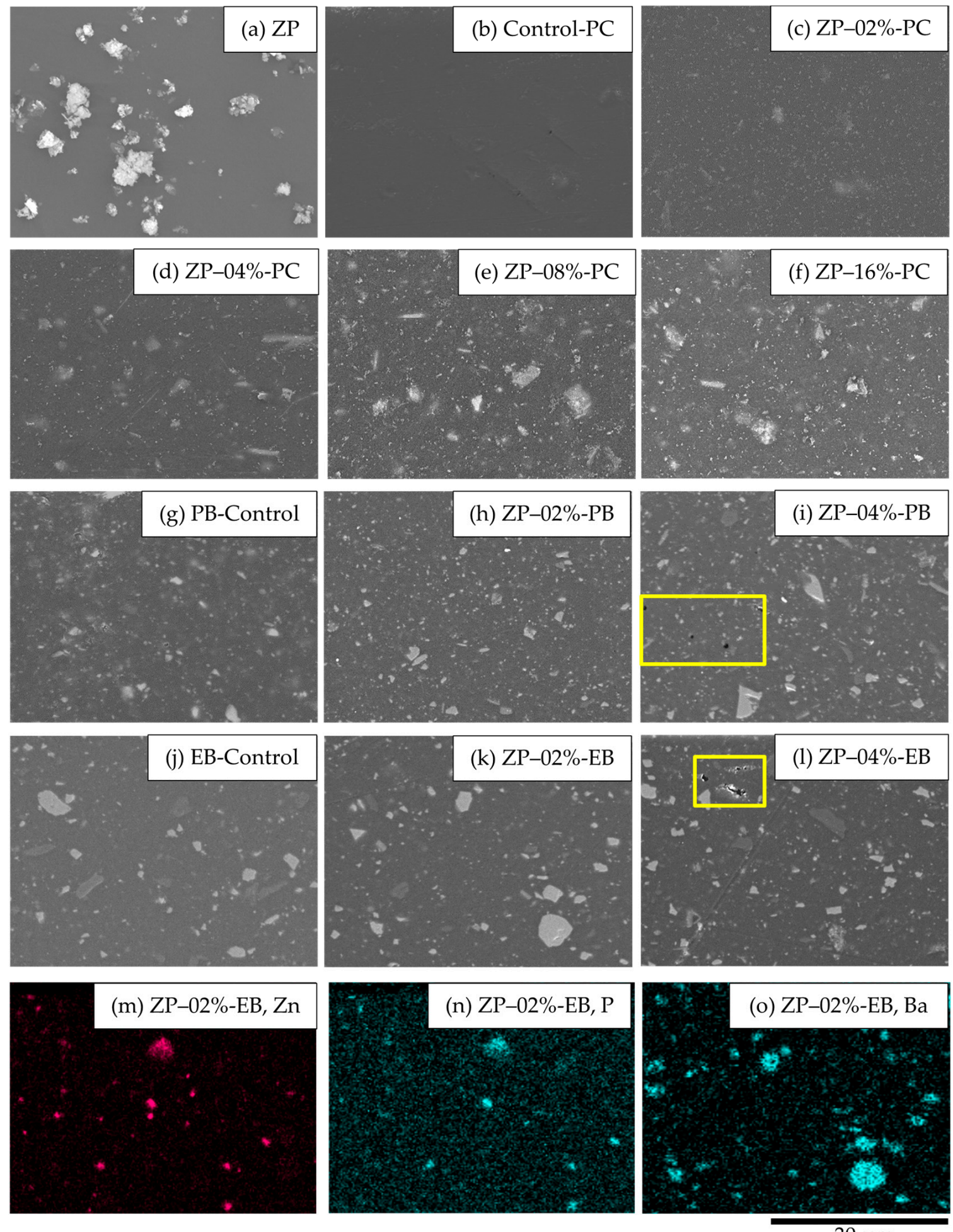

$30 \mu \mathrm{m}$

Figure 2. SEM images: (a) original ZP particles, cross-sections of ZP-containing coatings with different ZP contents in PC (b) Control-PC, (c) 2\%, (d) 4\%, (e) 8\%, (f) 16\%, PB ((g) Control-PB, (h) 2\%, (i) 4\%), and EB ((j) Control-EB, (k) 2\%, (l) 4\%); voids in highlighted areas; EDX maps of the coating prepared by ZP-02\%-EB (m) Zn, (n) P and (o) Ba. 

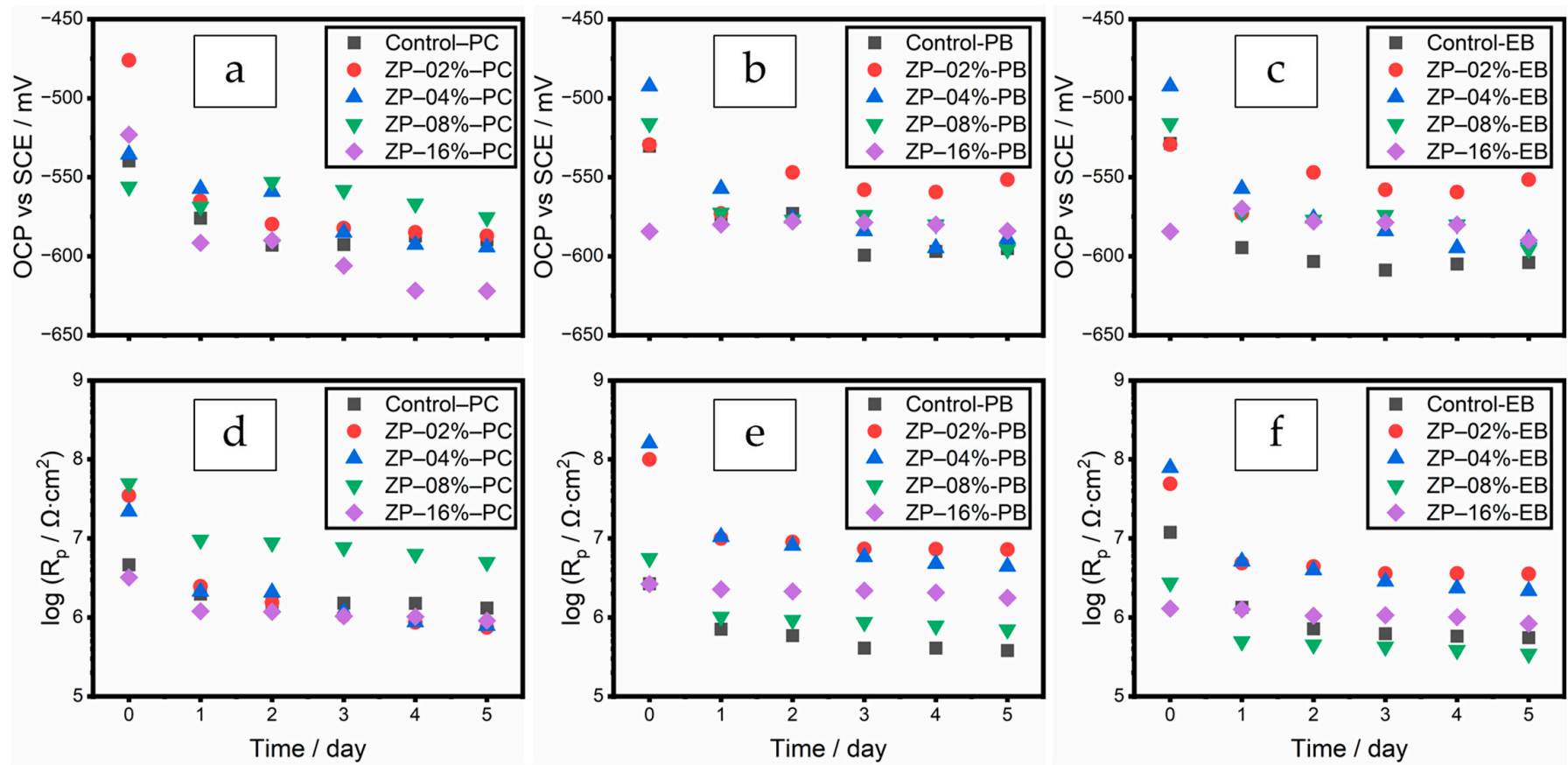

Figure 3. OCP and $R_{p}$ values of $Z P$ in $P C(\mathbf{a}, \mathbf{d}), P B(\mathbf{b}, \mathbf{e})$, and $E B(\mathbf{c}, \mathbf{f})$.

Compared with the polyester/TGIC clearcoat (Control-PC), the polyester/TGIC with filler $\mathrm{BaSO}_{4}$ (Control-PB) had slightly higher OCP values and $\mathrm{R}_{\mathrm{p}}$ values at the same order of magnitude. These values indicated that the filler alone did not improve the barrier effect. The additional defects in the coating film negated the benefit of increased tortuosity introduced by the filler.

In the three series of formulae, the formulae with the highest OCP values also had the highest $R_{p}$ values in each series, as also shown in Figure 3. Both values decreased over the time of immersion, indicating the electrolyte ingress and coating quality deterioration. The optimal dosages were 8,2 , and $2 \%$ in PC, PB, and EB systems, respectively. The latter two optimal dosages with the filler achieved higher OCP and $\mathrm{R}_{\mathrm{p}}$ values than $8 \% \mathrm{ZP}$ in the polyester/TGIC clearcoat, showing the synergistic effect of the two particles. The slight increases of the two values starting from day 4 for the two formulae demonstrated their self-repairing capability. Furthermore, the incorporation of the additional filler also decreased the overall material cost. Beyond the optima, both the OCP and $R_{p}$ decreased due to the additional defects in the coating films.

\subsubsection{EIS Spectra Analyses and Data Fitting Results}

\section{ZP $8 \%$ in PC (Polyester/TGIC Clearcoat)}

In addition to the OCP and $R_{p}$ measurements, EIS was performed for the optimal formulae to provide more detailed information on the coating transition during immersion. Figure 4 shows the spectra of the coating prepared by the formula ZP-08\%-PC.

The EIS spectrum of Day 0 (30 min) was fitted into the most used equivalent electrical circuit (EEC) for a defective coating film, as shown in Figure 4e. With the progression of electrolyte uptake, the spectra show patterns with three time constants. The spectra of Days 1, 3, and 5 were fitted by the EEC in Figure $4 \mathrm{f}$, and the obtained numerical values are listed in Table 4 . The components of the two EECs in common, namely $R_{s}, R_{\text {pore }}, R_{c t}, C E_{c o a t}$, and $\mathrm{CPE}_{\mathrm{dl}}$, are the solution resistance, coating pore resistance, charge transfer resistance, coating CPE (constant phase element), and double layer CPE in the coating-substrate interface, respectively. The CPEs, with a capacitor-like response, were used instead of pure capacitors to represent the inhomogeneity of the coating film and the interfaces [45]. 

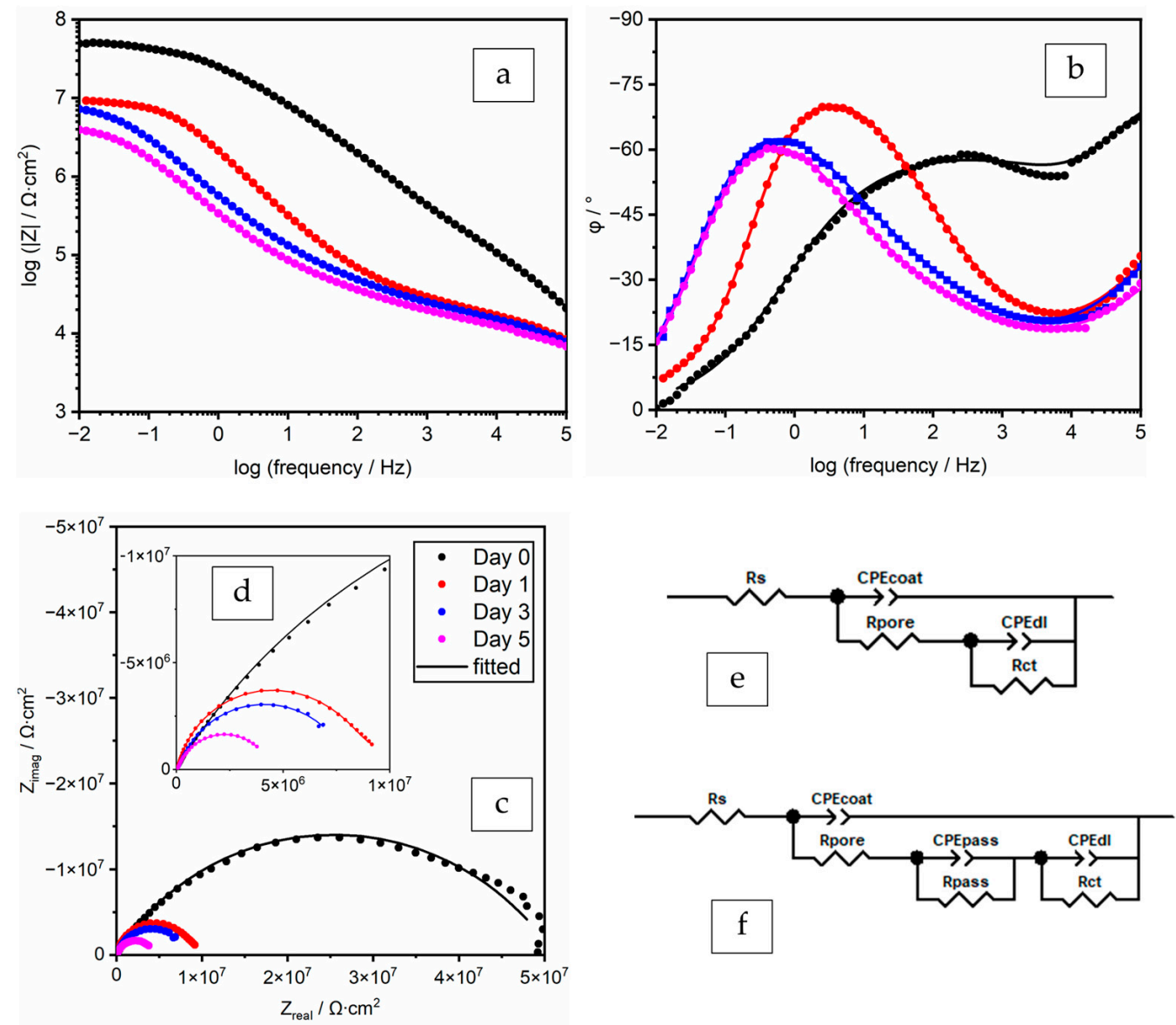

Figure 4. EIS spectra $(\mathbf{a}-\mathbf{c})$ and the Nyquist plot with the enlarged high-frequency region (d) and EECs for data fitting (e,f), formula ZP-08\%-PC.

Table 4. Fitted values of EEC components, ZP 8\% in PE clearcoat (ZP-08\%-PC).

\begin{tabular}{|c|c|c|c|c|c|c|c|c|c|c|}
\hline Time & $\mathrm{CPE}_{\text {coa }}$ & & $\mathbf{R}_{\text {pore }}$ & $\mathrm{CPE}_{\text {pass }}$ & & $\mathbf{R}_{\text {pass }}$ & $\mathrm{CPE}_{\mathrm{dl}}$ & & $\mathbf{R}_{\mathrm{ct}}$ & $x^{2}$ \\
\hline Days & $\begin{array}{c}\mathrm{Q}_{\text {coat }} / \\
\Omega^{-1} \cdot \mathrm{cm}^{-2} \cdot \mathrm{s}^{\alpha}\end{array}$ & $\alpha_{\text {coat }}$ & $\Omega \cdot \mathrm{cm}^{2}$ & $\begin{array}{c}Q_{\text {pass }} / \\
\Omega^{-1} \cdot \mathrm{cm}^{-2} \cdot \mathrm{s}^{\alpha}\end{array}$ & $\alpha_{\text {pass }}$ & $\Omega \cdot \mathrm{cm}^{2}$ & $\begin{array}{c}\mathrm{Q}_{\mathrm{dl}} / \\
\Omega^{-1} \cdot \mathrm{cm}^{-2} \cdot \mathrm{s}^{\alpha}\end{array}$ & $\alpha_{\mathrm{dl}}$ & $\Omega \cdot \mathrm{cm}^{2}$ & - \\
\hline 0 & $5.47 \times 10^{-10}$ & 0.844 & $1.29 \times 10^{5}$ & & & & $7.45 \times 10^{-9}$ & 0.618 & $5.11 \times 10^{7}$ & $3.26 \times 10^{-4}$ \\
\hline 1 & $1.62 \times 10^{-8}$ & 0.626 & $1.49 \times 10^{4}$ & $2.34 \times 10^{-6}$ & 0.371 & $2.20 \times 10^{7}$ & $7.66 \times 10^{-6}$ & 0.935 & $8.46 \times 10^{6}$ & $7.40 \times 10^{-5}$ \\
\hline 3 & $2.97 \times 10^{-8}$ & 0.592 & $1.55 \times 10^{4}$ & $2.16 \times 10^{-6}$ & 0.403 & $2.69 \times 10^{5}$ & $3.99 \times 10^{-7}$ & 0.853 & $7.93 \times 10^{6}$ & $9.89 \times 10^{-5}$ \\
\hline 5 & $3.81 \times 10^{-8}$ & 0.570 & $1.12 \times 10^{4}$ & $3.21 \times 10^{-6}$ & 0.379 & $1.46 \times 10^{5}$ & $7.05 \times 10^{-7}$ & 0.840 & $4.32 \times 10^{6}$ & $7.85 \times 10^{-5}$ \\
\hline
\end{tabular}

The two components $\mathrm{CPE}_{\text {pass }}$ and $\mathrm{R}_{\text {pass }}$ are the CPE and resistance of the newly formed passivation layer, consisting of iron phosphate. The addition of these components improves the data fittings quality, as indicated both visually and by the $\chi^{2}$ values. The large $R_{\text {pass }}$ values of $10^{7}-10^{5} \Omega \cdot \mathrm{cm}^{2}$ confirm the protective function of the newly formed passivation layer. Although the $R_{\text {pass }}$ value diminished over time, the additive was proven to be effective in extending the lifetime of the coating film.

$\mathrm{ZP} 2 \%$ with Filler $\mathrm{BaSO}_{4}$ in PB (Polyester/TGIC) and EB (Epoxy/DICY) Coatings

The spectra of the two coatings with $2 \% \mathrm{ZP}$ and filler $\mathrm{BaSO}_{4}$ in their formulae (ZP$02 \%$-PB and $\mathrm{ZP}-02 \%$-EB) are shown in Figures 5 and 6 , and the fitted values are listed in Tables 5 and 6, respectively. The spectra of the two formulae showed the pattern of barrier coatings with defects on Day 0 (30 min). The same EECs were utilized to achieve good EIS data fitting. 

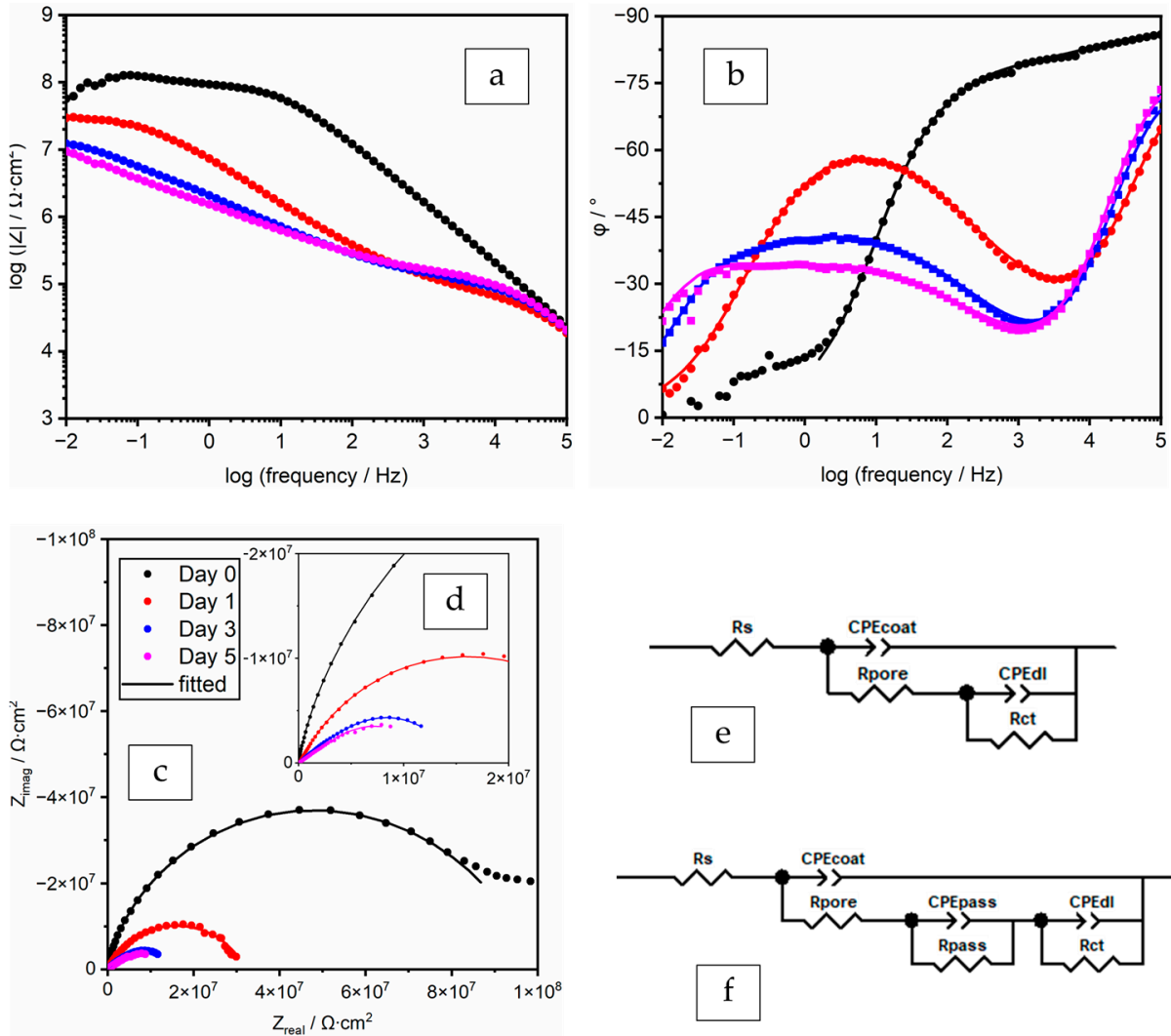

Figure 5. EIS spectra $(\mathbf{a}-\mathbf{c})$ and the Nyquist plot with the enlarged high-frequency region (d) and EECs for data fitting $(\mathbf{e}, \mathbf{f})$, coating prepared by the formula ZP-02\%-PB.
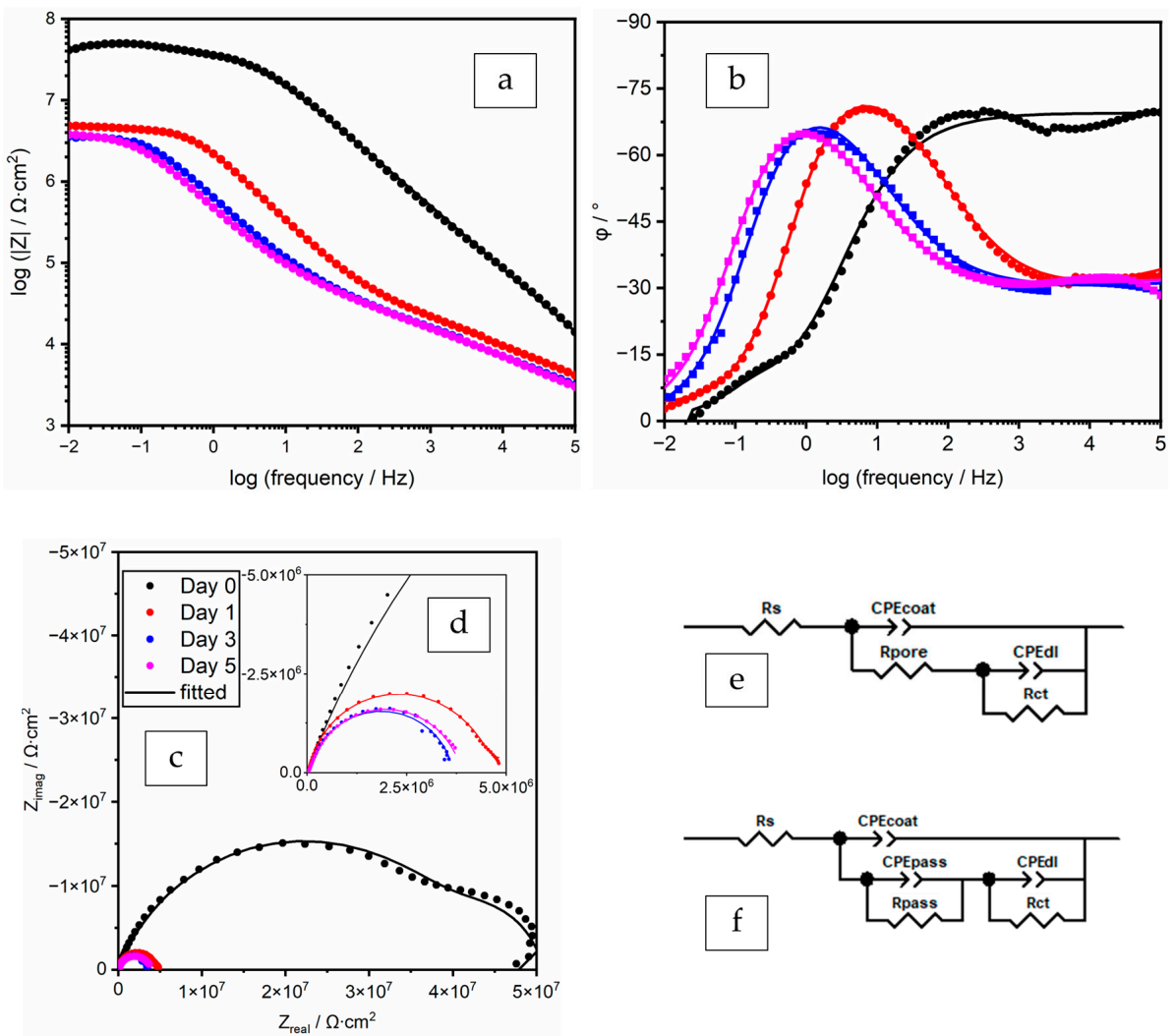

Figure 6. EIS spectra $(\mathbf{a}-\mathbf{c})$ and the Nyquist plot with the enlarged high-frequency region (d) and EECs for data fitting $(\mathbf{e}, \mathbf{f})$, coating prepared by the formula $\mathrm{ZP}-02 \%-\mathrm{EB}$. 
Table 5. Fitted values of EEC components, ZP 2\% in PB (ZP-02\%-PB).

\begin{tabular}{ccccccccccc}
\hline Time & $\mathbf{C P E}_{\text {coat }}$ & & $\mathbf{R}_{\text {pore }}$ & \multicolumn{2}{c}{$\mathbf{C P E}_{\text {pass }}$} & $\mathbf{R}_{\text {pass }}$ & $\mathbf{C P E}_{\mathrm{dl}}$ & $\mathbf{R}_{\mathrm{ct}}$ & $\chi^{2}$ \\
\hline Days & $\begin{array}{c}\mathrm{Q}_{\text {coat }} / \\
\Omega^{-1} \cdot \mathrm{cm}^{-2} \cdot \mathrm{s}^{\alpha}\end{array}$ & $\alpha_{\text {coat }}$ & $\Omega \cdot \mathrm{cm}^{2}$ & $\begin{array}{c}\mathrm{Q}_{\text {pass }} / \\
\Omega^{-1} \cdot \mathrm{cm}^{-2} \cdot \mathrm{s}^{\alpha}\end{array}$ & $\alpha_{\text {pass }}$ & $\Omega \cdot \mathrm{cm}^{2}$ & $\begin{array}{c}\mathrm{Q}_{\mathrm{dl}} / \\
\Omega^{-1} \cdot \mathrm{cm}^{-2} \cdot \mathrm{s}^{\alpha}\end{array}$ & $\alpha_{\mathrm{dl}}$ & $\Omega \cdot \mathrm{cm}^{2}$ & - \\
\hline 0 & $1.12 \times 10^{-10}$ & 0.962 & $1.61 \times 10^{6}$ & - & - & - & $3.89 \times$ & 0.671 & $9.85 \times 10^{7}$ & $8.30 \times 10^{-5}$ \\
1 & $2.66 \times 10^{-10}$ & 0.903 & $6.12 \times 10^{4}$ & $2.06 \times 10^{-7}$ & 0.491 & $1.12 \times 10^{5}$ & $3.24 \times 10^{-8}$ & 0.718 & $3.22 \times 10^{7}$ & $2.63 \times 10^{-4}$ \\
3 & $2.71 \times 10^{-10}$ & 0.900 & $1.03 \times 10^{5}$ & $1.81 \times 10^{-7}$ & 0.514 & $1.17 \times 10^{7}$ & $1.43 \times 10^{-6}$ & 0.949 & $4.04 \times 10^{6}$ & $2.76 \times 10^{-4}$ \\
5 & $1.97 \times 10^{-10}$ & 0.924 & $1.12 \times 10^{5}$ & $2.73 \times 10^{-7}$ & 0.457 & $4.22 \times 10^{6}$ & $9.07 \times 10^{-7}$ & 0.770 & $8.44 \times 10^{6}$ & $5.62 \times 10^{-4}$ \\
\hline
\end{tabular}

Table 6. Fitted values of EEC components, ZP 2\% in EB (ZP-02\%-EB).

\begin{tabular}{ccccccccccc}
\hline Time & $\mathbf{C P E}_{\text {coat }}$ & & $\mathbf{R}_{\text {pore }}$ & \multicolumn{2}{c}{$\mathrm{CPE}_{\text {pass }}$} & $\mathbf{R}_{\text {pass }}$ & $\mathbf{C P E}_{\mathrm{dl}}$ & $\mathbf{R}_{\mathrm{ct}}$ & $\chi^{2}$ \\
\hline Days & $\begin{array}{c}\mathrm{Q}_{\text {coat }} / \\
\Omega^{-1} \cdot \mathrm{cm}^{-2} \cdot \mathrm{s}^{\alpha}\end{array}$ & $\alpha_{\text {coat }}$ & $\Omega \cdot \mathrm{cm}^{2}$ & $\begin{array}{c}\mathrm{Q}_{\text {pass }} / \\
\Omega^{-1} \cdot \mathrm{cm}^{-2} \cdot \mathrm{s}^{\alpha}\end{array}$ & $\alpha_{\text {pass }}$ & $\Omega \cdot \mathrm{cm}^{2}$ & $\begin{array}{c}\mathrm{Q}_{\mathrm{dl}} / \\
\Omega^{-1} \cdot \mathrm{cm}^{-2} \cdot \mathrm{s}^{\alpha}\end{array}$ & $\alpha_{\mathrm{dl}}$ & $\Omega \cdot \mathrm{cm}^{2}$ & - \\
\hline 0 & $2.34 \times 10^{-9}$ & 0.772 & $4.44 \times 10^{7}$ & - & - & - & $1.42 \times 10^{-7}$ & 1.000 & $6.84 \times 10^{6}$ & $1.19 \times 10^{-3}$ \\
1 & $1.30 \times 10^{-8}$ & 0.634 & - & $3.51 \times 10^{-6}$ & 0.290 & - & $6.17 \times 10^{-8}$ & 0.958 & $4.18 \times 10^{6}$ & $1.56 \times 10^{-4}$ \\
3 & $6.87 \times 10^{-10}$ & 0.658 & - & $2.98 \times 10^{-6}$ & 0.346 & $1.53 \times 10^{5}$ & $3.09 \times 10^{-7}$ & 0.905 & $3.54 \times 10^{6}$ & $3.20 \times 10^{-4}$ \\
5 & $1.19 \times 10^{-9}$ & 0.650 & - & $4.59 \times 10^{-6}$ & 0.352 & $1.55 \times 10^{5}$ & $4.42 \times 10^{-7}$ & 0.894 & $3.72 \times 10^{6}$ & $4.33 \times 10^{-4}$ \\
\hline
\end{tabular}

The coating prepared by the formula $\mathrm{ZP}-02 \%-\mathrm{PB}$ exhibited higher performance than the one with ZP $8 \%$ in PC (polyester/TGIC clearcoat). The incorporation of filler enhanced the barrier effect of the coating film by increasing its tortuosity, as indicated by the higher $\mathrm{R}_{\text {pore }}$ and lower $\mathrm{CPE}_{\text {coat }}$ values than $\mathrm{ZP}-08 \%$-PC. The filler also facilitated the passivating effect of $\mathrm{ZP}$ and led to better corrosion protection, as $2 \%$ of the additive achieved higher $\mathrm{CPE}_{\text {pass }}$ values and $\mathrm{R}_{\text {pass }}$ values similar to the $8 \%$ in the clearcoat. Being different from the behavior of the passivation layer in the clearcoat, the change of the two values over time demonstrated a dynamic process in which the formation and deterioration of the passivation layer occurred simultaneously. With the gradual diffusion of the electrolyte into the coating-substrate interface through the pores, the formation of the passivation layer at the newly sealed defects overweighed the deterioration of the existing layer, as indicated by the initial increase of the $\mathrm{R}_{\text {pass }}$ value.

The spectra of the coating prepared by the formula ZP-02\%-EB on day 0 (30 $\mathrm{min})$ were fitted by the EEC in Figure 6e. On Days 1, 3, and 5, the obtained $R_{\text {pore }}$ values were close to zero, indicating that this feature does not play a role in restricting the current, and removing this component from the EEC improves the fitting quality, as indicated by the decreased $\chi^{2}$ values. For Day 1 , the fitted $R_{\text {pass }}$ value was extremely large, suggesting that this current pathway was inactive, so this component was removed from the EEC. The spectra of Day 1 showed a transient status of the passivation initiation, in which the passivation layer sealed the defects at the coating-substrate interface. As suggested by the large $R_{\text {pass }}$ value, the passivation layer formed instantaneously when the electrolyte reached the interface through a small number of defects in the coating film. The component $R_{\text {pore, }}$ which is usually in series with the two pairs of electrical components, i.e., $C P E_{\text {pass }}$ and $R_{\text {pass }}, C P E_{d l}$ and $R_{c t}$, as shown in Figure $4 f$, is not distinguishable from the $R_{\text {pass }}$ and $\mathrm{R}_{\mathrm{ct}}$ by the data fitting process. The fitting process was able to succeed only by removing $R_{\text {pore }}$ from the EEC. On Days 3 and 5, the decreasing $C P E_{\text {coat }}$ value indicated the repairing function of the additive.

At the same ZP dosage of $2 \%$, the polyester coating (Figure 5) outperformed the epoxy coating (Figure 6), as indicated by the lower coating film CPE values, higher resistance values, and more slowly decreasing resistances.

\subsection{Neutral Salt Spray Test Results}

Neutral salt spray tests were performed on the test panels with the same three series of formulae PC, PB and EB. Three identical panels of each formula were tested in parallel, and the creepages were measured every $500 \mathrm{~h}$. The elapsed times to reach a mean creepage 
value of $2 \mathrm{~mm}$ are plotted in Figure 7, and Figure 8 presents the panel photographs after the test. The salt spray results were different from those obtained by electrochemical methods. In PC (polyester/TGIC clearcoat), only the ZP dosage of $2 \%$ reached the salt spray hours of $1000 \mathrm{~h}$, but the additive showed no effect at any other dosages. In contrast, with the additional filler $\mathrm{BaSO}_{4}$, the salt spray hours of the coatings with the same $2 \% \mathrm{ZP}$ were significantly increased to $1500 \mathrm{~h}$ in both $\mathrm{PB}$ and $\mathrm{EB}$.

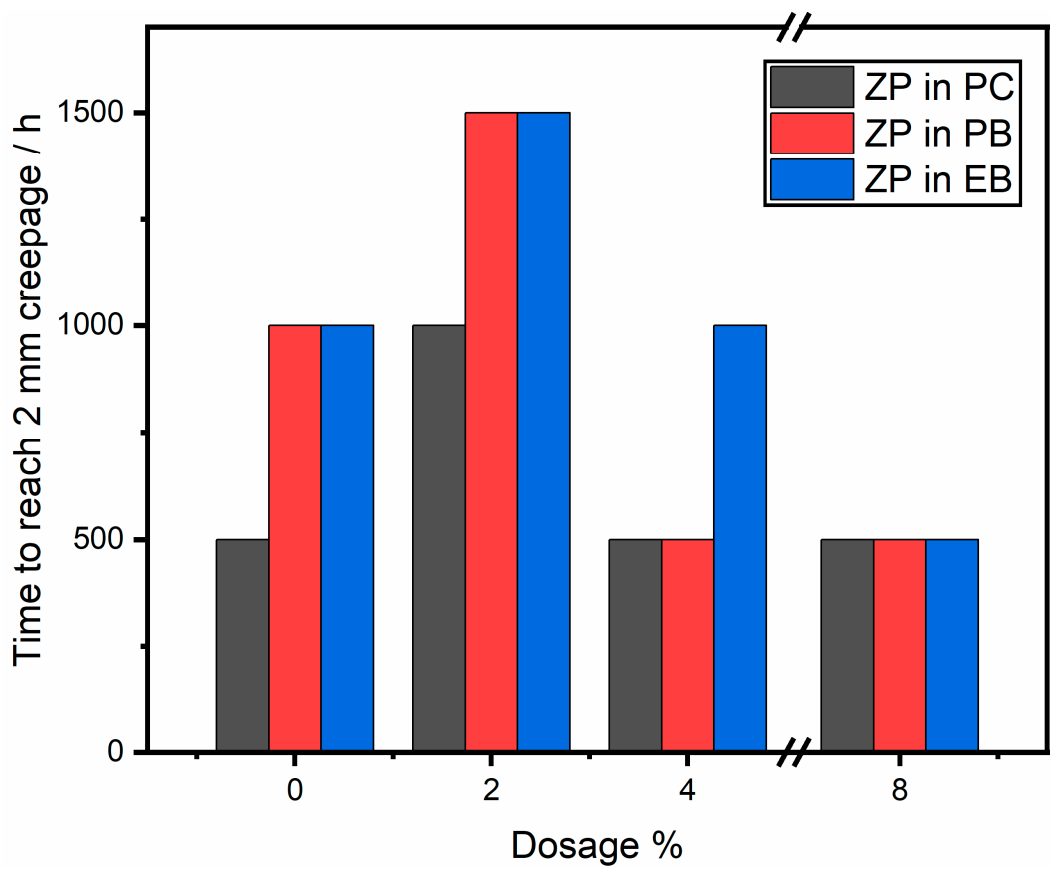

Figure 7. Salt spray results (time to reach $2 \mathrm{~mm}$ creepage) of the coatings prepared by the three series of formulae with ZP.

The panels had two $0.5 \mathrm{~mm}$ inscribed marks before salt fog exposure to bypass the step of electrolyte ingress into the coating film. The PC (polyester/TGIC clearcoat) had a dense film with a strong barrier and shielding effect, and as a result, the additive particles encapsulated in the polymer matrix could not migrate to the coating-substrate interface to exert active passivation promptly at the $2 \%$ dosage. Formulae at higher ZP dosages of $4 \%$ and $8 \%$ showed even worse salt spray results, and large delaminated regions formed alongside the scribe on both panels. The higher ZP content caused severe adhesion loss and coating delamination as a result of the increased coating permeability by the dissolution of $\mathrm{ZP}$, which the additive could not fully inhibit. The wet adhesion of the coating film was negatively affected by the high ZP content [46]. In contrast, the coated panels were intact without scribes in the immersion environment for electrochemical characterization to mimic the scenario without mechanical damage to the coating. The two types of performance testing yielded different overall results, such that the electrochemical tests probe the function of the intact, as-prepared coatings, whereas the salt spray tests investigate only the spread of damage after (artificial) mechanical failure of the coating, as schematized in Figure 9. This highlights the importance of employing test methods that probe the appropriate performance characteristics required to evaluate the service properties of concern. In this case, the salt spray tests are appropriate for evaluating the ability of mechanically damaged films to resist the spread of corrosion from the damage sites. They say nothing about the corrosion resistance of intact regions of the coating. In contrast, the electrochemical tests are perfectly suited to measuring the corrosion performance and deterioration of as-prepared, nominally intact coatings, a figure of merit that is more meaningful under the majority of service conditions faced by these coatings. 

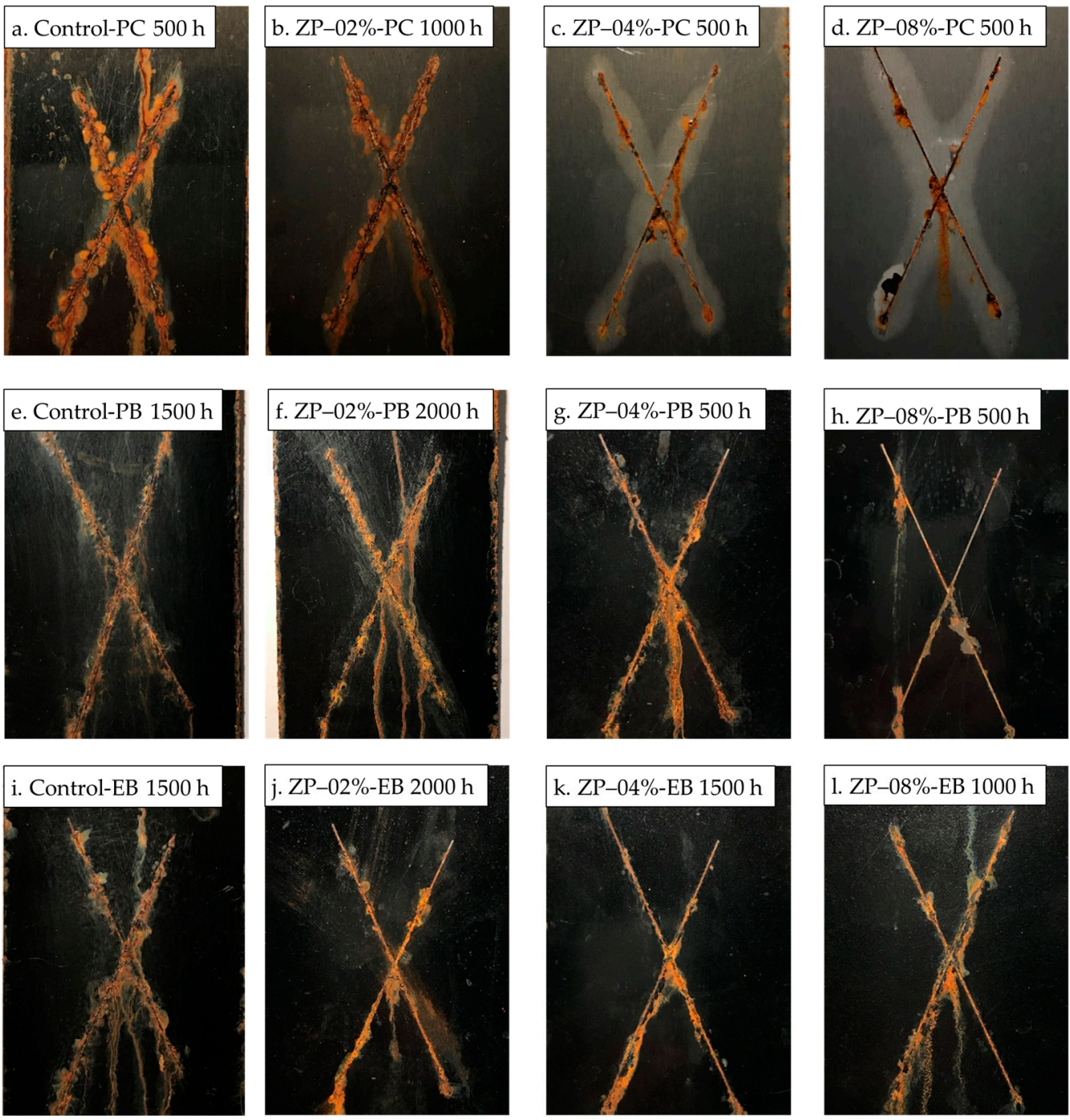

Figure 8. Panel photos after the salt spray test, ZP in PC (a-d), PB (e-h), and EB (i-1).
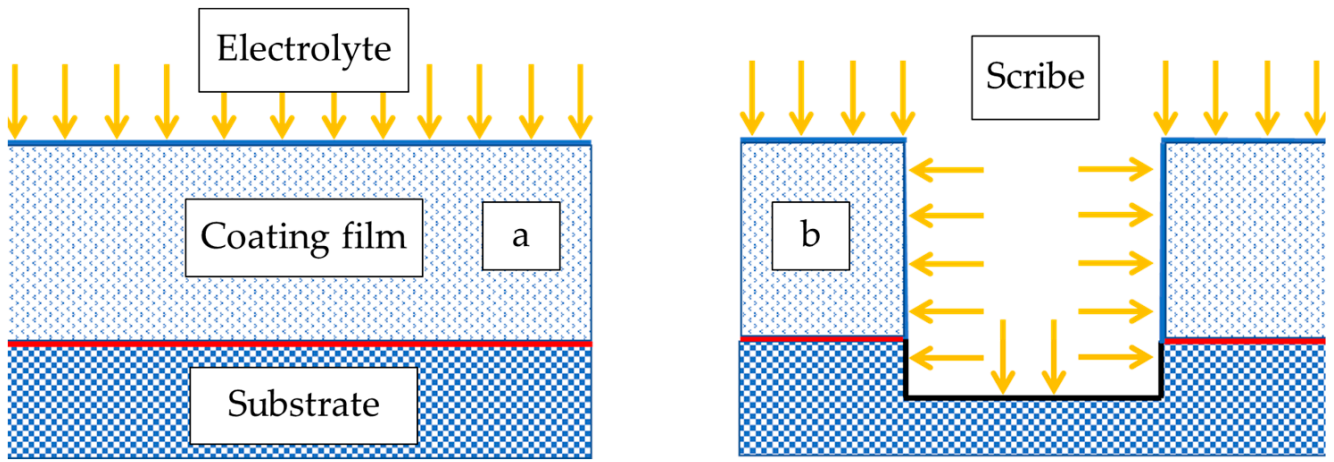

Figure 9. Schematic of two different exposure conditions and damage mechanisms arising in (a) electrochemical tests and (b) neutral salt spray tests.

The two test results demonstrated that the ZP additive exhibited better performance when the coating was more porous or when the coating layer was mechanically damaged. The choice of additive dosage and filler may depend on the end-use of the coatings. If the end-use involves mechanical damage of the coating, such as a walkway on a steel structure, then the additional filler can enhance the anti-corrosive property of the coating. Whereas in 
an underwater or underground structure where there is a low risk of abrasion or damage to the coating, a higher ZP dosage is favorable, as in the immersion test case.

\subsection{Confirmation of the Passivation Layer}

To confirm the passivation effect of the additive, low grazing angle XRD was performed on the coated panel of formula $\mathrm{ZP}-02 \%$-PC after the salt spray test. The main product of the passivation effect was identified as iron (II) phosphate [ferrous phosphate, $\left.\mathrm{Fe}_{3}\left(\mathrm{PO}_{4}\right)_{2}\right][13,24,47]$, as labeled in Figure 10a. Other corrosion products of the steel substrate included akaganeite $(\beta-\mathrm{FeOOH})$ and magnetite $\left(\mathrm{Fe}_{3} \mathrm{O}_{4}\right)$.
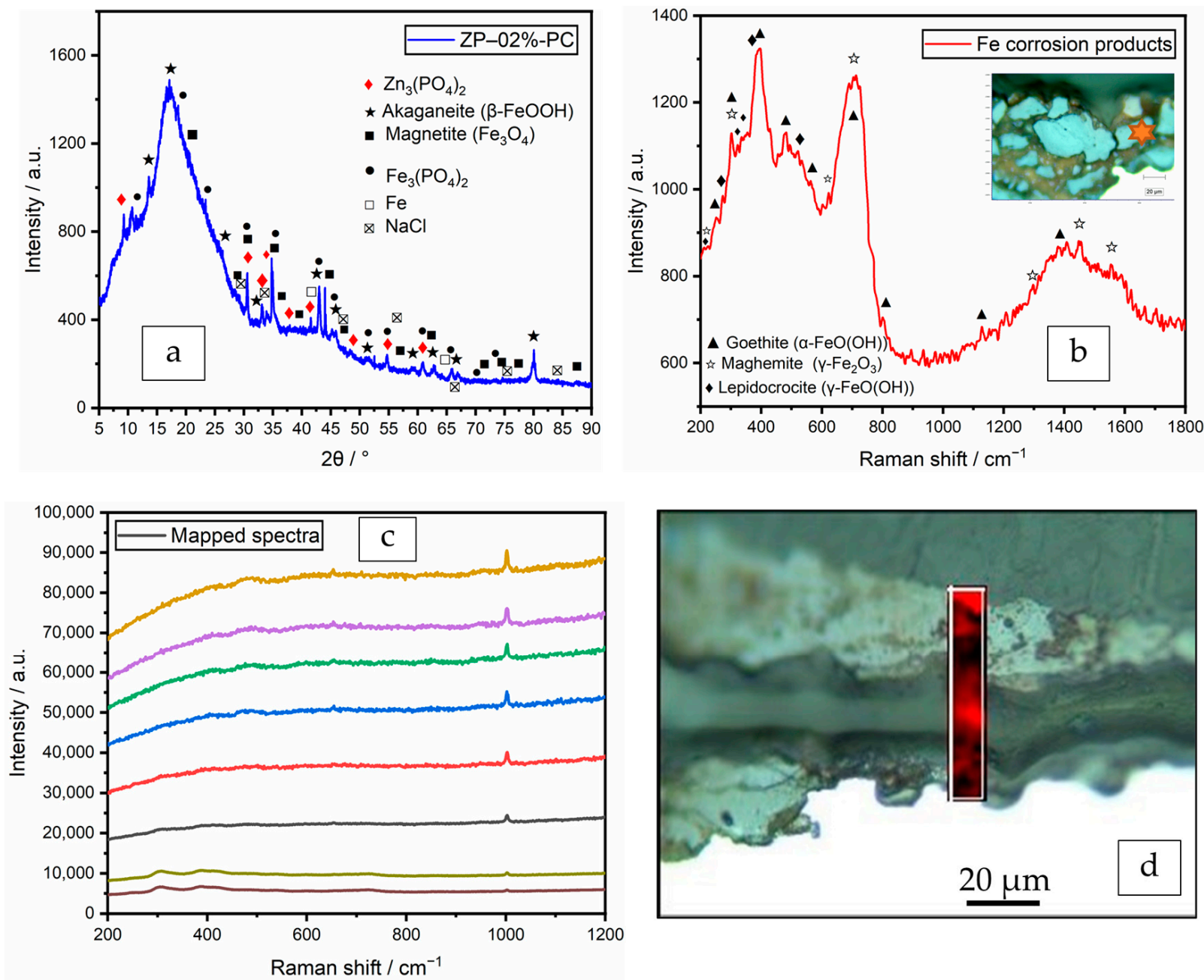

Figure 10. After salt spray test in polyester/TGIC clearcoat with $2 \% \mathrm{ZP}$, (a) XRD pattern, (b) Raman spectrum of Fe corrosion products, (c) spectra of Raman mapping, Raman spectra representing the range of signals observed from the mapped area (intensity has been offset to separate spectra for clarity) and (d) the mapped area with the intensity map at $1000 \mathrm{~cm}^{-1}$.

As a complementary technique to XRD, Raman laser spectroscopy was performed to further identify the corrosion and passivation products. The laser beam was focused on multiple corrosion sites across the cross-sections. Two more corrosion products of the steel substrate were identified as goethite $[\alpha-\mathrm{FeO}(\mathrm{OH})]$, maghemite $\left(\gamma-\mathrm{Fe}_{2} \mathrm{O}_{3}\right)$, and lepidocrocite $[\gamma-\mathrm{FeO}(\mathrm{OH})]$, as shown in Figure 10b; these iron oxides and hydroxyoxides are oxidation products of $\mathrm{Fe}(\mathrm{OH})_{2}$ [48].

Raman mapping was conducted on a cross-section of the delaminated area of the same test sample in order to locate the passivation layer. 8 of the 186 obtained spectra are plotted in Figure 10c, and the mapped area is shown in the optical image as in Figure 10d. 
All the spectra exhibit peaks around $1000 \mathrm{~cm}^{-1}$, which belong to the orthophosphate anion $[47,49]$. The presence of the phosphate indicated that a passivation layer was formed in the delaminated area and that the anion was able to migrate from the coating film to the coating-substrate interface to exert the inhibiting function.

\section{Conclusions}

In this study, an economical and environmentally friendly anti-corrosive additive zinc phosphate was incorporated into three powder coating systems, namely polyester/TGIC clearcoat, polyester/TGIC with filler $\mathrm{BaSO}_{4}$, and epoxy/DICY with the same filler. The polyester clearcoat with ZP had high gloss for outdoor applications and higher anticorrosive performance.

The additive significantly improved the anti-corrosive properties of the coating systems by forming a passivation layer. In the salt spray test, $2 \% \mathrm{ZP}$ significantly increased the salt spray hours, and the filler exhibited a synergistic function with the additive. With the increased ZP content in the same series, the higher solid content caused more severe coating delamination, and the anti-corrosive effect of the additive diminished. The addition of ZP increased the OCP and $\mathrm{R}_{\mathrm{p}}$ values of the coating films in the electrochemical test, and the optimal dosages were 8,2 , and $2 \%$, respectively. The EIS data analyses also confirmed that the polyester powder coating with filler exhibited the highest performance of the three coating systems. The polyester/TGIC coating with $2 \% \mathrm{ZP}$ and the filler was the most favorable arrangement as confirmed by both test methods, and it also had the benefit of higher UV-resistance.

The discrepancy between the results from the salt spray and electrochemical test methods for the clearcoat revealed the different coating behaviors under the two test conditions. They also highlighted the applicability of the two test methods. The salt spray test simulates the corrosion propagation after mechanical damage, whereas electrochemical techniques show both the electrolyte uptake and self-repairing at the localized corrosion sites during immersion. In industrial applications, the choice of the additive and filler dosages will ultimately vary depending on the application conditions and risk of mechanical damage while in service.

Author Contributions: Conceptualization, S.Y. and H.Z. (Hui Zhang); data curation, S.Y., J.H. and J.C.; formal analysis, S.Y., J.H., J.C., J.D.H., P.H. and J.J.N.; funding acquisition, H.Z. (Hui Zhang); investigation, S.Y., J.H., J.C. and I.B.; methodology, S.Y., J.H., J.C., H.Z. (Hui Zhang) and J.J.N.; project administration, H.Z. (Hui Zhang), J.Z., H.Z. (Haiping Zhang) and J.J.N.; resources, J.C., J.J.N. I.B. and H.Z. (Hui Zhang); software, S.Y. and J.D.H.; supervision, H.Z. (Hui Zhang), J.Z. and J.J.N.; validation, S.Y., J.H., J.C., P.H., H.Z. (Haiping Zhang), J.D.H. and J.J.N.; visualization, S.Y.; writing-original draft, S.Y.; writing-review and editing, J.H., J.C., J.J.N., J.D.H., H.Z. (Hui Zhang), P.H. and I.B. All authors have read and agreed to the published version of the manuscript.

Funding: This research was funded in part by The Natural Sciences and Engineering Research Council of Canada (NSERC) Discovery Grant, grant number RGPIN-2018-06256. The authors appreciate the partial funding for this work from NSERC Discovery Grant RGPIN-2018-06672.

Data Availability Statement: Not applicable.

Acknowledgments: The authors would like to express gratitude for the technical support provided by Mark Biesinger, Thalia Standish, Vahid Dehnavi, Heng-Yong Nie, Sridhar Ramamurthy, Charlie MacDonald, Baian Almusned, Heather Bloomfield, Bradley Kobe, Rebecca Sarazen, Jeffrey Daniel Henderson, Mary Jane Walzak and Susan Brown at Surface Science Western (www.surfacesciencewestern. com), and David Shoesmith, Dmitrij Zagidulin, Fraser Filice and Anna Dobkowska at the Department of Chemistry, Western University (The University of Western Ontario).

Conflicts of Interest: The authors declare no conflict of interest. 


\section{References}

1. Sørensen, P.A.; Kiil, S.; Dam-Johansen, K.; Weinell, C.E. Anticorrosive Coatings: A Review. J. Coat. Technol. Res. 2009, 6, 135-176. [CrossRef]

2. Walter, G.W. A Critical Review of the Protection of Metals by Paints. Corros. Sci. 1986, 26, 27-38. [CrossRef]

3. Turner, S.; Baskir, J.; Nunez, C. Powder Coatings: A Technology Review. Pollut. Prev. Rev. 1999, 9, 7-21.

4. Farrell, R. Powder Coatings. Met. Finish. 2010, 108, 100-107. [CrossRef]

5. Crapper, G. Powder Coatings. In Polymer Science: A Comprehensive Reference; Matyjaszewski, K., Möller, M., Eds.; Elsevier: Amsterdam, The Netherlands, 2012; Volume 10, pp. 541-566; ISBN 9780080878621.

6. Misev, T.A.; van der Linde, R. Powder Coatings Technology: New Developments at the Turn of the Century. Prog. Org. Coat. 1997, 34, 160-168. [CrossRef]

7. Zhang, H.; Yang, M.S.; Bhuiyan, M.T.I.; Zhu, J. Green Chemistry for Automotive Coatings: Sustainable Applications; RSC Publications: Cambridge, UK, 2019; pp. 368-394; ISBN 9781782629948.

8. El-ghaffar, M.A.A.; Abdel-wahab, N.A.; Sanad, M.A.; Sabaa, M.W. Progress in Organic Coatings High Performance Anti-Corrosive Powder Coatings Based on Phosphate Pigments Containing Poly (o-Aminophenol). Prog. Org. Coat. 2015, 78, 42-48. [CrossRef]

9. Viertel, J.; Neuer, L.; Mauch, B.; Czyborra, T. Project RepaKorr: Development of a Novel Single Coat, Direct to Metal Repair Coating with Outstanding Protection and Colour Retention Performance for Offshore Structures. Mater. Corros. 2017, 68, 1321-1325. [CrossRef]

10. Oliveira, C.G.; Ferreira, M.G.S. Ranking High-Quality Paint Systems Using EIS.Part I: Intact Coatings. Corros. Sci. 2003, 45, 123-138. [CrossRef]

11. Croll, S.G. Electrolyte Transport in Polymer Barrier Coatings: Perspectives from Other Disciplines. Prog. Org. Coat. 2018, 124, 41-48. [CrossRef]

12. Hussain, A.K.; Seetharamaiah, N.; Pichumani, M.; Chakra, C.S. Research Progress in Organic Zinc Rich Primer Coatings for Cathodic Protection of Metals - A Comprehensive Review. Prog. Org. Coat. 2021, 153, 106040. [CrossRef]

13. Hao, Y.; Liu, F.; Han, E.H.; Anjum, S.; Xu, G. The Mechanism of Inhibition by Zinc Phosphate in an Epoxy Coating. Corros. Sci. 2013, 69, 77-86. [CrossRef]

14. Jašková, V.; Kalendová, A. Anticorrosive Coatings Containing Modified Phosphates. Prog. Org. Coat. 2012, 75, 328-334. [CrossRef]

15. Naderi, R.; Arman, S.Y.; Fouladvand, S. Investigation on the Inhibition Synergism of New Generations of Phosphate-Based Anticorrosion Pigments. Dye. Pigment. 2014, 105, 23-33. [CrossRef]

16. Askari, F.; Ghasemi, E.; Ramezanzadeh, B.; Mahdavian, M. Synthesis and Characterization of the Fourth Generation of Zinc Phosphate Pigment in the Presence of Benzotriazole. Dye. Pigment. 2016, 124, 18-26. [CrossRef]

17. Bastos, A.C.; Ferreira, M.G.S.; Simões, A.M. Comparative Electrochemical Studies of Zinc Chromate and Zinc Phosphate as Corrosion Inhibitors for Zinc. Prog. Org. Coat. 2005, 52, 339-350. [CrossRef]

18. Darvish, A.; Naderi, R.; Attar, M.M. The Impact of Pigment Volume Concentration on the Protective Performance of Polyurethane Coating with Second Generation of Phosphate Based Anticorrosion Pigment. Prog. Org. Coat. 2014, 77, 1768-1773. [CrossRef]

19. Alibakhshi, E.; Ghasemi, E.; Mahdavian, M. Optimization of Potassium Zinc Phosphate Anticorrosion Pigment by Taguchi Experimental Design. Prog. Org. Coat. 2013, 76, 224-230. [CrossRef]

20. Alibakhshi, E.; Ghasemi, E.; Mahdavian, M. Corrosion Inhibition by Lithium Zinc Phosphate Pigment. Corros. Sci. 2013, 77, 222-229. [CrossRef]

21. Naderi, R.; Mahdavian, M.; Darvish, A. Electrochemical Examining Behavior of Epoxy Coating Incorporating Zinc-Free PhosphateBased Anticorrosion Pigment. Prog. Org. Coat. 2013, 76, 302-306. [CrossRef]

22. Puig, M.; Cabedo, L.; Gracenea, J.J.; Jiménez-Morales, A.; Gámez-Pérez, J.; Suay, J.J. Adhesion Enhancement of Powder Coatings on Galvanised Steel by Addition of Organo-Modified Silica Particles. Prog. Org. Coat. 2014, 77, 1309-1315. [CrossRef]

23. Puig, M.; Gimeno, M.J.; Gracenea, J.J.; Suay, J.J. Anticorrosive Properties Enhancement in Powder Coating Duplex Systems by Means of ZMP Anticorrosive Pigment. Assessment by Electrochemical Techniques. Prog. Org. Coat. 2014, 77, 1993-1999. [CrossRef]

24. Zubielewicz, M.; Gnot, W. Mechanisms of Non-Toxic Anticorrosive Pigments in Organic Waterborne Coatings. Prog. Org. Coat. 2004, 49, 358-371. [CrossRef]

25. Fishman, R.S.; Kurtze, D.A.; Bierwagen, G.P. Pigment Inhomogeneity and Void Formation in Organic Coatings. Prog. Org. Coat. 1993, 21, 387-403. [CrossRef]

26. Kalendova, A.; Veselý, D.; Kalenda, P. A Study of the Effects of Pigments and Fillers on the Properties of Anticorrosive Paints. Pigment. Resin Technol. 2006, 35, 83-94. [CrossRef]

27. Li, W.; Franco, D.C.; Yang, M.S.; Zhu, X.; Zhang, H.; Shao, Y.; Zhang, H.; Zhu, J. Investigation of the Performance of ATH Powders in Organic Powder Coatings. Coatings 2019, 9, 110. [CrossRef]

28. Schulze, K.A.; Zaman, A.A.; Söderholm, K.J.M. Effect of Filler Fraction on Strength, Viscosity and Porosity of Experimental Compomer Materials. J. Dent. 2003, 31, 373-382. [CrossRef]

29. Li, W.; Franco, D.C.; Yang, M.S.; Zhu, X.; Zhang, H.; Shao, Y.; Zhang, H.; Zhu, J. Comparative Study of the Performances of $\mathrm{Al}(\mathrm{OH}) 3$ and BaSO 4 in Ultrafine Powder Coatings. Processes 2019, 7, 316. [CrossRef]

30. Tan, B.; Thomas, N.L. Tortuosity Model to Predict the Combined Effects of Crystallinity and Nano-Sized Clay Mineral on the Water Vapour Barrier Properties of Polylactic Acid. Appl. Clay Sci. 2017, 141, 46-54. [CrossRef] 
31. Walter, G.W. A Critical Review of d.c. Electrochemical Tests for Painted Metals. Corros. Sci. 1986, 26, 39-47. [CrossRef]

32. Ding, J.; Zhao, H.; Xu, B.; Zhao, X.; Su, S.; Yu, H. Superanticorrosive Graphene Nanosheets through $\pi$ Deposition of Boron Nitride Nanodots. ACS Sustain. Chem. Eng. 2019, 7, 10900-10911. [CrossRef]

33. Ye, Y.; Zhang, D.; Li, J.; Liu, T.; Pu, J.; Zhao, H.; Wang, L. One-Step Synthesis of Superhydrophobic Polyhedral Oligomeric Silsesquioxane-Graphene Oxide and Its Application in Anti-Corrosion and Anti-Wear Fields. Corros. Sci. 2019, $147,9-21$. [CrossRef]

34. Pajkossy, T.; Jurczakowski, R. Electrochemical Impedance Spectroscopy in Interfacial Studies. Curr. Opin. Electrochem. 2017, 1, 53-58. [CrossRef]

35. Murray, J.N. Electrochemical Test Methods for Evaluating Organic Coatings on Metals: An Update. Part, I. Introduction and Generalities Regarding Electrochemical Testing of Organic Coatings. Prog. Org. Coat. 1997, 30, 225-233. [CrossRef]

36. Margarit-Mattos, I.C.P. EIS and Organic Coatings Performance: Revisiting Some Key Points. Electrochim. Acta 2020, 354,136725 [CrossRef]

37. Yang, L.H.; Liu, F.C.; Han, E.H. Effects of P/B on the Properties of Anticorrosive Coatings with Different Particle Size. Prog. Org. Coat. 2005, 53, 91-98. [CrossRef]

38. Rashvand, M.; Ranjbar, Z. Effect of Nano-ZnO Particles on the Corrosion Resistance of Polyurethane-Based Waterborne Coatings Immersed in Sodium Chloride Solution via EIS Technique. Prog. Org. Coat. 2013, 76, 1413-1417. [CrossRef]

39. Croll, S.G. Surface Roughness Profile and Its Effect on Coating Adhesion and Corrosion Protection: A Review. Prog. Org. Coat. 2020, 148, 105847. [CrossRef]

40. Biris, A.S.; Mazumder, M.K.; Yurteri, C.U.; Sims, R.A.; Snodgrass, J.; De, S. To Gloss and Texture Control of Powder Coated Films Part. Sci. Technol. 2011, 19, 199-217. [CrossRef]

41. Kunaver, M.; Klanjšek Gunde, M.; Mozetič, M.; Hrovat, A. The Degree of Dispersion of Pigments in Powder Coatings. Dye. Pigment. 2003, 57, 235-243. [CrossRef]

42. Seyedmehdi, S.A.; Zhang, H.; Zhu, J. Effect of Nanoclay on Electrical and Mechanical Properties of Polyurethane Conductive Coatings Filled with Nickel-Coated Carbon Fibers. Polym. Eng. Sci. 2013, 54, 1120-1125. [CrossRef]

43. Askari, F.; Ghasemi, E.; Ramezanzadeh, B.; Mahdavian, M. Mechanistic Approach for Evaluation of the Corrosion Inhibition of Potassium Zinc Phosphate Pigment on the Steel Surface: Application of Surface Analysis and Electrochemical Techniques. Dye. Pigment. 2014, 109, 189-199. [CrossRef]

44. Mahdavian, M.A.; Attar, M.M. Investigation on Zinc Phosphate Effectiveness at Different Pigment Volume Concentrations via Electrochemical Impedance Spectroscopy. Electrochim. Acta 2005, 50, 4645-4648. [CrossRef]

45. Bouvet, G.; Nguyen, D.D.; Mallarino, S.; Touzain, S. Analysis of the Non-Ideal Capacitive Behaviour for High Impedance Organic Coatings. Prog. Org. Coat. 2014, 77, 2045-2053. [CrossRef]

46. Negele, O.; Funke, W. Internal Stress and Wet Adhesion of Organic Coatings. Prog. Org. Coat. 1996, 28, 285-289. [CrossRef]

47. Lai, Y.M.; Liang, X.F.; Yang, S.Y.; Wang, J.X.; Cao, L.H.; Dai, B. Raman and FTIR Spectra of Iron Phosphate Glasses Containing Cerium. J. Mol. Struct. 2011, 992, 84-88. [CrossRef]

48. Misawa, T.; Hashimoto, K.; Shimodaira, S. The Mechanism of Formation of Iron Oxide and Oxyhydroxides in Aqueous Solutions at Room Temperature. Corros. Sci. 1974, 14, 131-149. [CrossRef]

49. Stoch, P.; Stoch, A.; Ciecinska, M.; Krakowiak, I.; Sitarz, M. Structure of Phosphate and Iron-Phosphate Glasses by DFT Calculations and FTIR/Raman Spectroscopy. J. Non-Cryst. Solids 2016, 450, 48-60. [CrossRef] 